www.jmscr.igmpublication.org

Impact Factor (SJIF): 6.379

Index Copernicus Value: 79.54

ISSN (e)-2347-176x ISSN (p) 2455-0450

crossrefDOI: https://dx.doi.org/10.18535/jmscr/v6i8.134

Journal Of Medical Science And Clinical Research

\title{
Observation of cases of antepartum hemorrhage in respect to fetal outcome, maternal morbidity and mortality in tertiary referral center
}

\author{
Authors \\ Archana Bharti ${ }^{1}$, Poonam Singh ${ }^{2}$, Neelam Nalini ${ }^{3}$ \\ ${ }^{1}$ Junior Resident, ${ }^{2}$ Associate Professor, ${ }^{3}$ Assistant Professor \\ Rajendra Institute of Medical Science, Ranchi, India
}

\begin{abstract}
Introduction: Antepartum hemorrhage (APH) is defined as bleeding from or into the genital tract after 28 weeks of pregnancy and before delivery of the baby. Placenta Previa and placental abruption are the major causes of APH in the third trimester of pregnancies and major contributors of maternal and fetal mortality and morbidity. To determine the incidence, relative frequency, etiopathogenesis and fetomaternal outcomes in respect to morbidity and mortality in APH in tertiary center, this study was carried out.

Material and Methods: This was one and half years study. Total 150 cases were included. Provisional diagnosis was made from detail clinical history, abdominal and vaginal examination. Ultrasonography and a gentle speculum examination was also done. Final diagnosis was made by findings at delivery and by examining the placenta after delivery. The cause of death was noted in case of maternal mortality.

Result: The incidence of APH was 1 in 57.86 pregnancies (1.72\%) in present study. Placenta Previa was the commonest cause. More common in 25-30 years of age, and in multigravida. Majority of women $(56.66 \%)$ had mixed type of bleeding (concealed and revealed). The total number of maternal death was 5. The main causes of death were hemorrhage, shock, renal failure and post-partum hemorrhage. Total perinatal mortality rate was $45.33 \%$ and most common cause was prematurity.

Conclusion: Good antenatal and postnatal care, adequately trained medical and paramedical staff, good referral hospital, good transport facility and institutional delivery can help in decreasing the maternal and fetal morbidity and mortality in APH.

Keywords: Antepartum hemorrhage, perinatal and maternal morbidity and mortality.
\end{abstract}

\section{Introduction}

Antepartum hemorrhage (APH) is defined as bleeding from or into the genital tract after 28 weeks of pregnancy and before delivery of the baby. ${ }^{[1]}$ It can be due to placenta praevia, abruption placentae, indeterminate cause or local causes of genital tract. Placenta previa and placental abruption are the major causes of antepartum hemorrhage in the third trimester of pregnancies and major contributors of obstetric hemorrhage in general. ${ }^{[2]}$ Each of these conditions has a prevalence rate of $0.5 \%$ to $2 \%$ in most parts of the world. ${ }^{[3-5]}$ Placenta praevia and placental abruption have been recognized as major obstetric complications that result in maternofetal mortality and morbidity.

Maternal mortality due to APH has significantly decreased in the developed countries due to better obstetrical outcome. In developing country, maternal and perinatal mortality is still very high 
due to associated problems like anemia, difficulties in transport in cases of emergency and restricted medical facilities. ${ }^{[6]}$ Maternal complications of APH are malpresentation, premature labour, postpartum haemorrhage, shock, retained placenta. It also includes higher rates of caesarean sections, peripartum hysterectomies, coagulation failure and death. Fetal complications are premature delivery low birth weight, intrauterine death, congenital malformations and birth asphyxia. ${ }^{[7-11]}$

The effect of the two bloody obstetric complications on perinatal health is multifactorial: blood loss, premature delivery, intrauterine growth restriction, the risk of perinatal asphyxia, the risk of sepsis, and hyperbilirubinemia. ${ }^{[12-15]}$ Perinatal mortality is considerably higher in APH than in normal pregnancy, either directly affecting the utero-placental circulation, which results in still birth babies or early interference which causes birth of premature babies. Perinatal mortality is especially high in cases of abruptio placentae. The perinatal mortality in placenta praevia has decreased over the years because of liberal blood transfusion, early caesarean section and better newborn care.Antepartum hemorrhage goes hand in hand with postpartum hemorrhage, as there is high incidence of postpartum hemorrhage in cases of antepartum hemorrhage. Untreated anemia is universally found in our scenario. Blood transfusion facilities are still inadequate in rural India. Late referral, lack of transport facilities and inadequate knowledge of medical and paramedical staff contributes to poor prognosis in cases of antepartum hemorrhage in developing countries. The aim of this present study is to find out the incidence of APH in tertiary referral center, relative frequency of placenta previa and abruptio placentae in APH, clinical aspect of APH in respect to aetiopathology and fetomaternal morbidity and mortality and to find out different measures for improvement of fetomaternal outcomes.

\section{Material and Methods}

The present study was conducted in the department of obstetrics and gynecology in tertiary care hospital. The period of study was one and half years. All booked and unbooked cases of APH were included in this study. Total number of 150 women with APH and followed through the immediate puerperium were included. Detail clinical and obstetric histories were taken including age, parity, socioeconomic status, religion, literacy, antenatal checkup prior to admission, about the time of onset of bleeding, its nature and associated complains like pain abdomen, color and the amount of bleeding were also noted. They were asked about any abdominal trauma, coitus, or pelvic examination. Patients were also asked about the previous bouts of bleeding prior to present bleeding. Detail obstetrical history and history of any chronic illness were noted. Family history of twin, hypertension and diabetes also noted. Provisional diagnosis was made, clinically from the presenting symptoms and signs. Ultrasonography was carried out in almost all cases except in few cases in which immediate intervention was done on admission. Then abdominal and vaginal examinations were done gently and if needed vaginal examination done in the operation theatre with full preparation for caesarean section. If abruption placentae was suspected then gentle pelvic examination was done to assess whether patient was in labor or not and to decide the line of management. Whenever, there was confusion in the diagnosis with placenta Praevia, internal examination (Double set up examination) was done in operation theatre.

Vaginal examination was strictly avoided when patient was in exsanguinated state, in diagnosed cases of major degree of placenta previa confirmed by ultrasonography previously, associated complicating factors such as malpresentation, pregnancy in previous caesarean section, known cases of CPD. A gentle speculum examination was done to establish any cervical or vaginal lesion only when major causes 
of APH were excluded. Final diagnosis was made by finding at vaginal delivery or caesarean section and by examining the placenta after delivery. Routine blood test, coagulation profile and urine tests were also done. Ultrasonography was done to localize the site of placenta, to determine the degree and type of placenta previa and retro placental clots. The lie, presentation, gestational age of the fetus was also noted. General management of all patients was done by IV fluid, antibiotics, blood transfusion, monitoring of input and output in case of shock. Obstetric management in case of abruption in labor by doing amniotomy and augumanting labour, if heavily bleeding with alive baby immediate caesarean section was done. In cases of placenta Previa with immature fetus and no active bleeding, was managed in hospital conservatively. Rest, steroid cover was given to them. In minor degree placenta Praevia more than 36weeks gestation with slight bleeding, no obstetrics contraindication and induction of labor was done. In addition, in cases of major degree of placenta Praevia with mature fetus, caesarian section was done. In cases of maternal mortality, cause of death was noted. Finally, after delivery baby was examined thoroughly.

\section{Results}

During the period of one and half years of study, out of 8680 patients admitted in Obstetrical Emergency, 150 cases were of APH. The incidence of APH in this period was 1 in 57.86 pregnancies $(1.72 \%)$. In the present study, it was found that $98 \%$ of the cases were of emergency admission and majority had no proper antenatal checkup. Placenta Previa was the commonest cause of third trimester (32-36weeks) hemorrhage in this study (Table 1). More common age group was between 25-30 years, with the maximum numbers of cases were found in $5^{\text {th }}$ gravida or more.In $46.66 \%$ of women with abruptio placentae, there were sign of toxemia of pregnancy. Character of bleeding in placenta Previa was recurrent (25\%), continuous $(63.88 \%)$ and $11.11 \%$ cases were not bleed. Majority of women $(56.66 \%)$ had mixed (revealed and concealed) type of bleeding. The number of cases of malpresentation (22.21\%) was definitely high with placenta Praevia. In the present study, $22.21 \%$ of women had malpresentation, the commonest was breech presentation, $18.51 \%$ and in $3.70 \%$, there was shoulder presentation. In $0.92 \%$ of women, twin pregnancy was present. Cesarean section rate in placenta Previa was $78.43 \%$ and caesarean hysterectomy occurred in one case. One case died prior to delivery. Vaginal delivery rate was $70 \%$ and caesarean section rate was $30 \%$ in cases of abruptio placentae. The total number of maternal death was $5(3.33 \%)$. The main causes of death were APH, shock, renal failure and post-partum hemorrhage. Maximum number of maternal deaths occurred in $5^{\text {th }}$ gravida or more. The study shows the perinatal mortality was $41.66 \%$ in placenta Praevia and $76.66 \%$ in abruptio placentae. Total perinatal mortality rate was $45.33 \%$ (Table 4). In this study perinatal mortality was higher in premature babies (Table $5)$.

Table 1: Distribution of cases of placenta praevia, abruptio placentae and other cases of third trimester haemorrhage

\begin{tabular}{|l|c|c|}
\hline Cause of APH & Number of cases & Percentage (\%) \\
\hline \hline Placenta praevia & 108 & 72 \\
\hline \hline Abruptio placentae & 30 & 20 \\
\hline Indeterminate & 9 & 6 \\
\hline \hline Excessive show & 3 & 2 \\
\hline \hline Total & 150 & 100 \\
\hline
\end{tabular}

The table indicates that placenta praevia was the commonest cause of third trimester haemorrhage in this series 
Table 2: Period of gestation at which the separation of placenta occurred in abruptio placentae

\begin{tabular}{|l||r||r||}
\hline Period (weeks) & $\begin{array}{r}\text { Number of cases of } \\
\text { abruptio placentae }\end{array}$ & $\begin{array}{r}\text { Percentage } \\
(\mathbf{\%})\end{array}$ \\
\hline \hline $28-32$ & 17 & 56.66 \\
\hline \hline $33-36$ & 3 & 10.0 \\
\hline \hline $37-40$ & 10 & 33.33 \\
\hline \hline Total & 30 & 100 \\
\hline
\end{tabular}

The table shows that $56.66 \%$ of abruptio placentae occurred within 28 -32 week

Table 3: Period of gestation at which patient admitted with placenta praevia

\begin{tabular}{||c||c|c||}
\hline Period (weeks) & $\begin{array}{c}\text { Number of cases of } \\
\text { placenta praevia }\end{array}$ & $\begin{array}{c}\text { Percentage } \\
(\mathbf{\%})\end{array}$ \\
\hline \hline $28-32$ & 31 & 28.70 \\
\hline \hline $33-36$ & 60 & 55.55 \\
\hline $37-40$ & 17 & 15.74 \\
\hline Total & 108 & 100 \\
\hline
\end{tabular}

Maximum number of cases of placenta praevia sought admission between 33-36 weeks. 12 women were completely asymptomatic.

Table 4: Perinatal outcome in cases of Antepartum haemorrhage

\begin{tabular}{|l|c|c|c|}
\hline Perinatal outcome & Placenta praevia & Abruptio placentae & Others \\
\hline \hline Still birth & 35 & 21 & 2 \\
\hline \hline Early neonatal death & 10 & 2 & - \\
\hline \hline Healthy after one week & 62 & 7 & 10 \\
\hline
\end{tabular}

The study shows the perinatal mortality was $41.66 \%$ in placenta praevia and $76.66 \%$ in abruptio placentae. Total perinatal mortality rate was $45.33 \%$

Table 5: Perinatal mortality in relation to the Period of gestation

\begin{tabular}{|l|c||c|c|}
\hline Period of gestation & No. of cases & Perinatal mortality & Percentage (\%) \\
\hline \hline Less than 34 weeks & 56 & 39 & 69.64 \\
\hline \hline Between 34-37 weeks & 12 & 6 & 50.00 \\
\hline \hline Between 38-40 weeks & 82 & 25 & 30.48 \\
\hline
\end{tabular}

This table shows perinatal mortality was higher in premature babies.

\section{Discussion}

The total number of admission in labor room during one and half years was 8680. Only 150 cases of bleeding per vagina during third trimester that is after 28 weeks of gestation were included in this study. The incidence of antepartum hemorrhage in the present study is $1.72 \%$ which is significantly less as compared to Sheikh et $\mathrm{al}^{15]}$ $(5.4 \%)$ and Singhal et $\mathrm{al}^{[6]}(3.01 \%)$. Most of the cases was unbooked similar to the study done in Hyderabad. ${ }^{[15]}$ The majority of the cases of antepartum hemorrhage in this study were due to placenta Praevia comparable to a study done in southwestern Nigeria ${ }^{[16]}$. Out of 150 cases, there were 108 cases $(72 \%)$ of placenta Praevia, 30 cases $(20 \%)$ of abruptio placentae, 9 cases $(6 \%)$ of indeterminate origin and 3 cases $(2 \%)$ of excessive show. The incidence of placenta praevia is $1.72 \%$, significantly higher in the present study as compared to Sheikh et $\mathrm{al}^{[15]}(51.7 \%)$ and Singhal et $\mathrm{al}^{[6]}(52.64 \%)$ and $1.5 \%$ reported from Oshogbo ${ }^{[17]}$ and lower than $5.4 \%$ documented in Pakistan $^{[15]}$ and $15.3 \%$ from Qatar ${ }^{[18]}$. The incidence of abruptio placentae in the present study (20\%) is significantly lesser as comparable to Sheikh et al ${ }^{[15]}(44.6 \%)$ and Singhal et $\mathrm{al}^{[6]}$ (29.65\%). The incidence of undetermined APH of present study (6\%) as compared to Singhal et al ${ }^{[6]}$ $(17.7 \%)$ and Sheikh et $\mathrm{al}^{[15]}(2.5 \%)$.The risk of placenta Praevia and abruptio placentae increases with advancing age and parity. ${ }^{[19,20]}$ In this study, $43.51 \%$ of women with placenta Praevia and 
$43.33 \%$ of women with abruptio placentae were between 25-30 years of age. It was seen that maternal hypertension predisposed to placental abruption. ${ }^{[21]}$ In this series $46.66 \%$ of women with abruptio placentae had toxemia of pregnancy. In the present study there were $5(16.66 \%)$ cases of abruptio placentae with concealed hemorrhage, 8 (26.66\%) with revealed bleeding and 17 (56.66\%) with mixed type of hemorrhage. In placenta Praevia bleeding is usually painless. In present study, $69(63.88 \%)$ cases with placenta Praevia had continuous bleeding, $12(11.11 \%)$ cases had no bleeding at all and remaining $27(25 \%)$ cases had recurrent episodes of bleeding.

Management of women with placenta praevia depends on the duration of pregnancy and severity of bleeding. If the fetus is immature, the usual aim is to allow pregnancy to continue until baby had a reasonable chance to survive ex-utero. If bleeding occurred at 37 weeks of pregnancy, it was best to deliver the fetus. Macafee 1945 introduced this policy of conservative management. In present study, there were 91 women with placenta Previa who were admitted before $37^{\text {th }}$ weeks. In 61 women pregnancy had to be terminated immediately because of severe hemorrhage and 1 woman died undelivered. The rest 28 women were treated conservatively in hospital under close supervision. One patient had to undergo caesarean hysterectomy for massive P.P.H.

Caesarean section is the accepted method of delivery in cases of placenta Previa. In present study 85 women $(78.43 \%)$ out of 108 with placenta Previa underwent caesarean section much higher than in Hyderabad study $57.1 \%^{[15]}$ and 21 women $(19.62 \%)$ with minor degree of placenta Praevia, vaginal delivery was attempted. One case was died prior to delivery. In one case, caesarean hysterectomy was done for massive P.P.H. In present study, eight cases of morbidly adherent placenta were found. Primary post-partum hemorrhage was observed in 17 cases and caesarean hysterectomy was done in one $(0.93 \%)$ case. Early diagnosis and prompt treatment is the mainstay in the management of accidental hemorrhage because maternal and fetal prognosis worsens if the interval between placental separation and delivery is more than six - eight hours. Spontaneous vaginal delivery is the preferred method of treatment in abruptio placentae. In the present study vaginal delivery was done in 21 women $(70 \%)$ out of 30 cases of placental abruption in this series. Caesarean section was the method of delivery employed in ninewomen $(30 \%)$. Caesarean rate in placenta Previa in present study was $(78.43 \%)$ and in abruptio placenta $(30 \%)$ which is much higher as compared to Singhal et $\mathrm{al}^{[6]}(48.80 \%)$ and Sheikh et $\mathrm{al}^{[15]}(57.1 \%)$

Non-placental causes of third trimester bleeding were encountered in nine cases. In the present study, three cases were wrongly diagnosed as having antepartum hemorrhage. They subsequently delivered vaginally. There were nine cases in which the cause could not be ascertained in which eight delivered normally and in one woman, cesarean section was done. Maternal mortality is death of woman during pregnancy or child birth or puerperium. Maternal mortality is still higher in developing countries.

In present study, maternal mortality was $3.33 \%$. Two cases were died out of 108 cases of placenta Previa and three were died out of 30 cases of abruptio placentae. No maternal death reported in indeterminate group. Antepartum haemorrhage, hypovolemic shock, renal failure and postpartum hemorrhage were prime causes of death in the present study and it was found that maternal death is high in multigravida. Maternal complication, postpartum hemorrhage $(.66 \%)$ was less in the present study as compared to Singhal et $\mathrm{al}^{[6]}$ $(21.84 \%)$ and Sheikh et al ${ }^{[15]}(19 \%)$ and Oshogbo $(7.1 \%)^{[16]}$. The decreased incidence of postpartum hemorrhage in present study may be due to prophylactic measures taken for prevention of postpartum hemorrhage such as prophylactic use of prostaglandin F2Alpha, methyl ergometrine, and uterine and ovarian artery ligation. Also, Maternal mortality has begun to decline due to availability of blood, blood products and higher 
antibiotics, Maternal mortality rate is comparable between Singhal et al ${ }^{[6]}(2.21 \%)$ and present study $(3.33 \%)$.

APH is responsible for a large percentage of perinatal death all over the world and found to be elevated more than threefold, when there is bleeding any time in pregnancy. The total perinatal mortality rate is $46.97 \%$ in the present study, is significantly higher than Singhal et al ${ }^{[6]}$ $(23.70 \%)$ however, comparable to Sheikh et $\mathrm{al}^{[15]}$ $(49.66 \%)$. The incidence of low birth weight and prematurity is much less in present study $(69.64 \%)$ as compared to Singhal et $\mathrm{al}^{[6]}(83.18 \%)$ and comparable to Oshogbo $68.4 \%{ }^{[16]}$ The stillbirth rate was $38.6 \%$ in our study, while other studies have quoted a stillbirth rate of $50.2 \%$ and $22.2 \%^{[15,16]}$ in cases of antepartum hemorrhage. This may likely be related to the rate at which timely intervention is instituted as hemorrhage exposed the fetuses to hypoxia and ultimately death $^{[15]}$. Perinatal mortality correlates with the severity of abruption, period of gestation at which hemorrhage occurs, weight of fetus, amount of concealed hemorrhage and maternal hypertension. Perinatal mortality is also high in indeterminate group. In present study it was $1.33 \%$.Several studies have shown that placenta Previa and placenta abruption are known to triple the rate of perinatal mortality primarily due to prematurity ${ }^{[14,22,23,]}$. The high perinatal mortality $(69.64 \%)$ in present study was mainly due to prematurity. This could be reduced by choosing the optimum time for planning delivery, after careful assessment of the maturity of the fetus. In this respect ultrasonography and simple test for pulmonary maturity, LS ratio had an invaluable role to play. The most important factor is the relatively poor perinatal outcome in this study, compared to that in sophisticated centers was the lack of specialized unit for expert neonatal care for the very low birth-weight baby.

\section{Conclusion}

The maternofetal mortality in APH can be reduced by educating the people about various government schemes for pregnant women, about the value of antenatal and postnatal care, benefits of a small family size, awareness of the services offered at P.H.C \& referral centers. Better transport system and connectivity from village to referral centers and adequate skilled staff round the clock. There should be intensive obstetric care unit with equipped neonatology at referral centers. Facilities of blood transfusion, caesarean section and ultrasonography should be available for 24 hours. Early recognition and timely management of the case can improve maternofetal mortality and morbidity.

\section{References}

1. Dutta DC. Antepartum haemorrhage.In Konar. HL ed. Textbook of obstetrics. $6^{\text {th }}$ Ed. Kolkatta: New central book agency: 2006;243-46.

2. Q. Yang, S.W. Wen, K. Phillips, L. Oppenheimer, D. Black, and M. C. Walker. "Comparison of maternal risk factors between placental abruption and placenta previa". The American Journal of Perinatology. 2009;26:279-86.

3. Y. Oyelese and C.V.Ananth, "Placental abruption," Obstetrics andGynecology. 2006; 108:1005-16.

4. K.E. Francois and M.R.Foley. "Antepartum and post-partum haemorrhage," in Obstetrics: Normal and Problem Pregnancies S.G. Gabbe, J.R. Niebyl, and J.L. Simpson,Eds., Churchill Levingstone, NewYork, NY,USA.5thedition.2007; 45866.

5. S. L. Clark, "Placenta previa and abruption," in Maternal-Fetal Medicine: Principles and Practice, R.K.Creasy and R. Resnik, Eds., p.713,WB Saunders Company, Philadelphia, Pa,USA,5th edition 2004.

6. Singhal S, Nymphaea, Nanda S. Maternal and perinatal outcome in antepartum haemorrhage: A study at a tertiary care referral institute. The Internet Journal of 
Gynaecology and Obstetrics 2008;9(2): 5580/1b6.

7. Williams Obstetrics. Obstetrical haemorrhage. In Cunningham FG, Leveno KJ, Bloom SL, Hauth JC et al. 22nd Edition. McGraw Hill Companies, Inc: 2005: 810-820.

8. Konje JE, Taylor DJ. Bleeding in late pregnancy. In James DK, Steer PJ, Weiner $\mathrm{CP}$, Gonik B, editors. High risk pregnancy management options, 2nd ed. London: Harcourt 2000.

9. Neilson JP. Antepartum haemorrhage. In: Edmonds DK editor. Dewhursts textbook of Obstetrics and Gynaecology for post graduates 6th ed. Blackwell scientific London. Oxford. 1995:164-74.

10. Neilson JP. Intervention for treating placental abruption (Cochrane review) In: Cochrane Library, Issue 3, 2003. Oxford: Update software (Level I).

11. Khosla A, Dahiya V, Sangwan K, Rathore S. Perinatal outcome in antepartum haemorrhage. J ObstetGynae India.1989; 71-3.

12. R. Giordano, A. Cacciatore, P. Cignini, R. Vigna, and M. Romano. "Antepartum Haemorrhage," Journal of Prenatal Medicine. 2010;.4;12-6.

13. T. Rosenberg, G. Pariente, R. Sergienko, A. Wiznitzer, and E. Sheiner, "Critical analysis of risk factors and outcome of placenta previa". Archives of Gynecology and Obstetrics. 2011;284:47-51.

14. J. M. G. Crane, M. C. Van den Hof, L. Dodds, B. A. Armson, and R. Liston, "Maternal complications with placenta previa," American Journal of Perinatology. 2000;17:101-5.

15. Sheikh F, Khokhar S, Sirichand P, Shaikh R.A study of antepartum haemorrhage: Maternal and perinatal outcome. Medical Channel 2010;16(2): 268-71.
16. Ikechebelu JI, Onwusulu DN. Placenta praevia: Review of clinical presentation and management in a Nigerian teaching hospital. Niger J Med. 2007;16:61-4.

17. Adekanle A, Adeyemi A, Fadero F. Antepartum haemorrhage in LAUTECH Teaching Hospital, South-Western Nigeria. J Med Sci. 2011;2:1243-7.

18. Bener A, Saleh NM, Yousafzai MT. Prevalence and associated risk factors of ante-partum hemorrhage among Arab women in an economically fast growing society. Niger J ClinPract.

19. Cleary-Goldman J, Malone FD, Vidaver J et al:Impact of maternal age on obstetric outcome.ObstetGynecol 105:983,2005

20. BabinszkiA,Kerenyi T, Torok O, et al : Perinatal outcome in grand and great grand multiparity : Effects of parity on obstetric risk factors. Am J ObstetGynecol 1999;181:669.

21. Giordano R, Cacciatore A, Cignini P, Vigna R, Romano M. Antepartum haemorrhage. J Prenat Med. 2010;4:12-6.

22. C.V. Ananth, J.C. Smulianand A.M. Vintzileos. "The effect of placenta previa on neonatal mortality: a population-based study in theUnitedStates, 1989 through 1997" The American Journal of Obstetrics and Gynecology. 2003;188:1299-1304.

23. C.M. Lam, S.F.Wong, K.M.Chow, and L.C. Ho. "Women with placenta praevia and antepartum haemorrhage have a worse outcome than those who do not bleed before delivery". Journal of Obstetrics and Gynaecology. 2000;20:27-31. 